\title{
Intestinal cell migration damage induced by enteropathogenic Escherichia coli strains
}

\author{
P.A. Cavalcante, M.M.G. Prata, P.H.Q.S. Medeiros, A.V. Alves da Silva, J.S. Quetz, M.A.V. Reyes, \\ T.S. Rodrigues, A.K.S. Santos, S.A. Ribeiro, H.N. Veras, M.D. Bona, M.S.M.G. Amaral, \\ F.A.P. Rodrigues, I.F.N. Lima, A. Havt and A.A.M. Lima \\ Departamento de Fisiologia e Farmacologia, Faculdade de Medicina, Instituto de Biomedicina, \\ Universidade Federal do Ceará, Fortaleza, CE, Brasil
}

\begin{abstract}
Epithelial cell migration is an essential response to enteric pathogens such as enteropathogenic Escherichia coli (EPEC). This study aimed to investigate the effects of EPEC infection on intestinal epithelial cell migration in vitro, as well as the involvement of type III secretion system (T3SS) and Rho GTPases. Crypt intestinal epithelial cells (IEC-6) were infected with EPEC strains (E2348/69, $\Delta$ escF, and the LDI001 strain isolated from a malnourished Brazilian child) and commensal E. coli HS. Wound migration and cell death assays were performed at different time-points. Transcription and expression of Rho GTPases were evaluated using real-time PCR and western blotting. Overall, EPEC E2348/69 reduced migration and increased apoptosis and necrosis levels compared to EPEC LDI001 and E. coli HS strains. Moreover, EPEC LDI001 impaired cell migration at a higher level than E. coli $\mathrm{HS}$ and increased necrosis after 24 hours compared to the control group. The different profiles of virulence genes between the two wild-type EPEC strains, characterized by the absence of espL and nleE genes in the LDI001, might explain the phenotypic results, playing significant roles on cell migration impairment and cell death-related events. Moreover, the type III secretion system is determinant for the inhibition of intestinal epithelial cell migration by EPEC 2348/69, as its deletion prevented the effect. Active Rac1 concentrations were increased in E2348/69 and LDI001-infected cells, while the T3SS-deficient strain did not demonstrate this activation. This study contributes with valuable insight to characterize the mechanisms involved in the impairment of intestinal cell migration induced by EPEC.
\end{abstract}

Key words: Enteropathogenic Escherichia coli; Intestinal cell migration; Type III secretion system

\section{Introduction}

Enteropathogenic Escherichia coli (EPEC) was recently associated with higher risk of infant death in a multicenter case-control study on diarrhea in developing countries (1). In addition, the high prevalence of some strains of EPEC in both symptomatic and asymptomatic individuals from developing countries has gained significant attention $(2,3)$.

The central mechanism of EPEC pathogenesis is a lesion characterized by attaching and effacing (A/E) and reorganization of the actin cytoskeleton of host cells, causing the destruction of intestinal microvilli (4). Furthermore, EPEC has been associated with altered intestinal arrier function, including reduction of intestinal surface area and redistribution of tight junctions $(5,6)$. These detrimental effects occur by interactions of host cell molecules with effector proteins injected by EPEC into the epithelium through a type III secretion system (T3SS) (4). However, pathogenesis of damage due to EPEC is not well characterized (7).
Migration of crypt cells to the injured area is one of the first host responses to intestinal epithelial injury (8); members of the Rho GTPases family are required for coordinating this dynamic and complex response (9). Within this group, Cdc42 and Rac1 are involved in the formation of filopodia and lamellipodia, respectively, whereas RhoA mediates cellular contractility and formation of focal adhesions (10).

Although EPEC effector proteins, e.g., Map, EspT, and $\mathrm{EspH}$, alter the function of Rho GTPases to enhance cell adhesion and promote pathogen survival (11), there is apparently no report regarding effects of EPEC on intestinal cell migration and its Rho-related alterations. Furthermore, there is a lack of information regarding major EPEC virulence factors involved in this damage. To better understand this phenomenon, we used a model of intestinal cell migration to investigate and compare the effects of two EPEC strains (the prototype E2348/69 and LDI001, isolated

Correspondence: A.A.M. Lima: <alima@ufc.br> 
from a malnourished child) and a commensal $E$. coli strain (HS). We further determined whether T3SS was necessary for this effect and the role of Rho GTPases.

\section{Material and Methods}

\section{Bacterial strains}

Bacterial strains used in this study are listed in Table 1. The EPEC strain E2348/69 and E. coli strain HS were kindly provided by Dr. James Nataro, University of Virginia (USA), whereas the EPEC strains (both mutant and complemented) were graciously provided by Dr. Michael Donnenberg, University of Maryland (USA). EPEC strain LDI001 was isolated from the feces of a malnourished non-diarrheic child participating in the case-control Brazilian study from the MAL-ED network (12). Specimens were cultured on MacConkey agar plates; five colonies positive for lactose fermentation with features suggestive of E. coli were selected and characterized using biochemical tests and molecular biology assays, as previously described (13). Bacterial adherence to HEp-2 was also determined (14). Bacterial DNA was evaluated (multiplex PCRs) to detect genes encoding various virulence factors (Supplementary Table S1).

\section{Cell culture}

The IEC-6 (CRL-1592 ${ }^{\mathrm{TM}}$ ) and HEp-2 (CCL-23) cell lines were purchased from the American Type Culture Collection (ATCC, USA). The IEC-6 cell line, derived from rat small intestinal epithelium, was used at passages 20-30. Cells were cultured in Dulbecco's modified Eagle medium (DMEM, Gibco BRL, USA) containing heat-inactivated 5\% fetal bovine serum (Gibco BRL), $40 \mathrm{mg} / \mathrm{mL}$ insulin (SigmaAldrich, St. Louis, MO), $50 \mathrm{U} / \mathrm{mL}$ penicillin (Gibco BRL), $50 \mathrm{mg} / \mathrm{mL}$ streptomycin (Gibco BRL), and $1 \mathrm{mM}$ sodium pyruvate (Gibco BRL). The HEp-2 cells (passages 9-12), derived from HeLa cell contamination and commonly used to assess bacterial adherence (14), were cultured in Minimal Essential Medium (MEM, Gibco BRL) supplemented with $10 \%$ fetal bovine serum, $100 \mathrm{U} / \mathrm{mL}$ penicillin, and $100 \mathrm{mg} / \mathrm{mL}$ streptomycin. All cells were maintained at $37^{\circ} \mathrm{C}$ and $90 \%$ humidity, in an atmosphere containing $5 \% \mathrm{CO}_{2}$.

\section{Bacterial infections}

Bacteria were cultured on MacConkey agar plates for 18-24 $\mathrm{h}$ and then suspended in glutamine-free DMEM at absorbances of 0.04 to 0.12 (measured at $600 \mathrm{~nm}$, i.e., OD600). A portion of the culture was assessed for growth on agar plates to confirm the number of CFU per $\mathrm{mL}$. The EscF-complemented strain was used as described (15). E. coli cultures were added to cell cultures for $3 \mathrm{~h}$. Cells were then washed and glutamine-free DMEM supplemented with $200 \mu \mathrm{g} / \mathrm{mL}$ gentamicin was added to cultures.

\section{Cell migration assay}

The IEC-6 cells were seeded on 12-well plates $\left(2.5 \times 10^{5}\right.$ cells per well) and grown in DMEM. Upon reaching confluence $(48 \mathrm{~h}$ ), $5 \mu \mathrm{L}$ of mitomycin $\mathrm{C}$ (final concentration $5 \mu \mathrm{g} / \mathrm{mL}$; Roche, USA) was added to each well and cells were incubated at $37^{\circ} \mathrm{C}$ for $15-20 \mathrm{~min}$. Then, cells were washed, and the monolayer was cut (sterile blade) from the center of the well to the periphery. Wells were washed again, and cells were infected according to the protocol described above. Cells were washed once with PBS, and at 2, 6, 12, and $24 \mathrm{~h}$ after treatment with gentamicin were photographed using an inverted microscope (Nikon E400, Japan) at a magnification of $10 \times$. The number of migrating cells was counted in an area of $0.1 \mathrm{~mm}^{2}$ overlaying the center of the cut, as previously described (16). Images were analyzed using Image J Pro Plus software, version 5.0 (Media Cybernetics, USA).

\section{Flow cytometric analysis of apoptotic and necrotic cell death}

A RC-Anxf-T100 Apoptosis Assay Kit (Exbio, CZ) was used to quantify apoptotic and necrotic cells. Cells were collected 2, 6, 12, and $24 \mathrm{~h}$ after infection. Cells were trypsinized, centrifuged, and washed before incubation with annexin $\mathrm{V}$ and propidium iodide $(\mathrm{PI})$ to detect apoptotic and necrotic cells, respectively. Samples were processed using a FACS Calibur flow cytometer (Becton Dickinson, USA), and data analyzed with CellQuest ${ }^{\circledR}$ software (Becton Dickinson).

Table 1. Bacterial strains used in this study.

\begin{tabular}{|c|c|c|}
\hline Strains & Description & References \\
\hline EPEC strain E2348/69 & $\begin{array}{l}\text { Wild-type strain (serotype } \mathrm{O} 127: \mathrm{H} 6 \text { belonging to } E \text {. coli phylogroup B2), originally } \\
\text { isolated from an outbreak of diarrhea in children, isolated in Taunton, UK }\end{array}$ & $(31)$ \\
\hline EPEC strain LDI001 & $\begin{array}{l}\text { Wild-type strain isolated from feces of a undernourished child without diarrhea } \\
\text { in Fortaleza, CE, Brazil }\end{array}$ & $(12)$ \\
\hline EPEC strain UMD731 & $\Delta e s c F ;$ lacks functioning T3SS & $(15)$ \\
\hline$\Delta$ escF/escF EPEC strain & T3SS restored & $(15)$ \\
\hline E. coli strain HS & Nonpathogenic E. coli & $(40)$ \\
\hline
\end{tabular}

EPEC: enteropathogenic Escherichia coli. 


\section{Quantitative PCR analysis}

Total RNA was isolated using the RNeasy Plus Mini Kit (Qiagen, Inc., USA) from uninfected IEC-6 cells or cells infected for $3 \mathrm{~h}$ with $10^{6} \mathrm{CFU}$ per $\mathrm{mL}$ of each EPEC strain. The iScript cDNA Synthesis $\mathrm{Kit}^{\mathrm{TM}}$ (Bio-Rad, USA) was used to synthesize cDNAs according to the manufacturer's instructions. Transcriptions of RhoA, Rac1, and Cdc42 were used to investigate mechanisms of crypt cell migration (17) using the IQ5 Real-Time PCR Detection System (Bio-Rad). The reference gene ywhaz encoding phospholipase $A_{2}$ was used for these experiments (18). All primers and conditions for qPCR are shown in Table 2. The qPCR reactions were performed in reaction mixtures containing $10 \mu \mathrm{L}$ of $\mathrm{iQ}$ Supermix (Bio-Rad) in a standard amplification buffer containing optimal concentrations of DNA polymerase, dNTPs, buffer, and saline, plus $2 \mu \mathrm{L}$ of each primer pair $(0.2 \mathrm{mM}), 1 \mu \mathrm{L}$ of cDNA, and nucleasefree water (final volume of $20 \mu \mathrm{L}$ ). To ensure amplification specificity, each reaction was performed by increasing the temperature by $0.5^{\circ} \mathrm{C}$ at $15 \mathrm{~s}$ intervals, starting from the annealing temperature of the primers and ending at $95^{\circ} \mathrm{C}$ (71 cycles). Data were analyzed with the $\Delta \Delta \mathrm{Ct}$ method (19).

\section{Western blot analysis and active Rac1}

Western blotting was performed as described (15), with some modifications. Briefly, IEC- 6 cells were grown on plates with 12 wells for $48 \mathrm{~h}$ and then infected with EPEC strains for $3 \mathrm{~h}$. Cells were scraped in RIPA lysis buffer supplemented with protease inhibitor (Sigma) on ice. The suspension was centrifuged $\left(10 \mathrm{~min}, 4^{\circ} \mathrm{C}, 180 \mathrm{~g}\right)$ and the supernatant collected. Protein concentrations were measured using PierceTM BCA protein assay kit (Thermo Scientific, USA). Then, proteins were separated by an SDS-polyacrylamide and transferred to polyvinylidene difluoride (PVDF) membranes by electrophoresis. The PVDF membranes were blocked with $5 \%$ bovine serum albumin for $1 \mathrm{~h}$ and incubated overnight with the following primary antibodies: anti-Rac1 mouse monoclonal IgG (1:250) and anti-GADPH (glyceraldehyde-3-phosphate dehydrogenase) rabbit polyclonal IgG (1:500; Santa Cruz Biotechnology, USA). Membranes were washed in Trisbuffered saline with Tween and then incubated for $1.5 \mathrm{~h}$ with secondary antibodies (diluted 1:500). Chemiluminescent detection using Clarity Western ECL Substrate (BioRad) was performed, and bands were captured using the ChemiDoc system (Bio-Rad). Densitometric quantification of bands was done with Image J software, version 1.6.0 (National Institutes of Health, USA). To measure Rac1 activation, a pull-down assay, the rhotekin binding domain affinity precipitation for Rac1-GTP, was used according to the manufacturer's protocol (Cytoskeleton, USA) and SDSPAGE was performed as described above.

\section{Statistical analysis}

Experiments were performed on three days, and data are reported as means $\pm S E$. Differences between groups were compared with one-way ANOVA (followed by Bonferroni's post-test) or an unpaired Student's $t$-test. All analyses were performed using GraphPad Prism, version 5.0 (GraphPad, USA). The confidence interval was $95 \%$, and differences were considered significant when $\mathrm{P}<0.05$.

\section{Results}

\section{EPEC strain LDI001 displayed localized adherence and harbored several EPEC virulence genes}

Before the use of experimental infections, virulence of EPEC strains was characterized. Both EPEC strains (E2348/69 and LDI00) displayed localized adherence patterns on HEp-2 cell lines, whereas the commensal strain (HS) had no particular pattern of adhesion (data not shown). Furthermore, both EPEC strains equally harbored

Table 2. Description of genes, GenBank accession numbers, RT-qPCR primers, and PCR conditions.

\begin{tabular}{|c|c|c|c|c|}
\hline Gene & GenBank accession number & Primer sequences $\left(5^{\prime}-3^{\prime}\right)$ & PCR Conditions & References \\
\hline \multirow[t]{3}{*}{ rhoA } & NM_057132.3 & TGGTGATGGAGCTTGTGGTAAG & $20 \mathrm{~s}-95^{\circ} \mathrm{C}$ & $(17)$ \\
\hline & & AACATCAGTGTCTGGGTAGGAG & $20 \mathrm{~s}-58.5^{\circ} \mathrm{C}$ & \\
\hline & & & $45 \mathrm{~s}-72^{\circ} \mathrm{C}$ & \\
\hline \multirow[t]{3}{*}{ rac1 } & NM_134366.1 & CAGCTGGACAGGAAGATTATGAC & $20 \mathrm{~s}-95^{\circ} \mathrm{C}$ & $(17)$ \\
\hline & & CCACTAGGATGATGGGAGTATTG & $20 \mathrm{~s}-61^{\circ} \mathrm{C}$ & \\
\hline & & & $45 \mathrm{~s}-72^{\circ} \mathrm{C}$ & \\
\hline \multirow[t]{3}{*}{$c d c 42$} & NM_171994. & GCTTGTCGGGACCCAAATTG & $20 \mathrm{~s}-95^{\circ} \mathrm{C}$ & $(17)$ \\
\hline & & ACACCTGCGGCTCTTCTTCG & $20 \mathrm{~s}-61^{\circ} \mathrm{C}$ & \\
\hline & & & $45 \mathrm{~s}-72^{\circ} \mathrm{C}$ & \\
\hline \multirow[t]{3}{*}{ ywhaz } & NM_013011.3 & GCTACTTGGCTGAGGTTGCT & $20 \mathrm{~s}-95^{\circ} \mathrm{C}$ & $(18)$ \\
\hline & & TGCTGTGACTGGTCCACAAT & $20 \mathrm{~s}-60^{\circ} \mathrm{C}$ & \\
\hline & & & $45 \mathrm{~s}-72^{\circ} \mathrm{C}$ & \\
\hline
\end{tabular}

In all qPCR reactions, the initial denaturation step was the same for all primers $\left(95^{\circ} \mathrm{C}\right.$ for $\left.3 \mathrm{~min}\right)$. 
most virulence genes (eae, bfpA, espB, espD, tir, nleB, map, espJ, espL, espC, espZ, espH, ler, espG, nleE, nleF, cesT, espP, nleD, and nleC), except for espL and nleE genes, which were present only in the prototype strain.

\section{EPEC strains impaired migration of IEC -6 cells}

To determine optimal inoculum size for migration analysis, infections were done using $\mathrm{MOI}$ (multiplicity of infection) 1, 10, and 100 of EPEC E2348/69. Reductions in migrated cells after $6 \mathrm{~h}$ was dependent on the size of the inoculum; $50 \%$ of the maximum reduction occurred using an inoculum of $10^{6} \mathrm{CFU}$ per $\mathrm{mL}$, which was chosen for subsequent tests (MOI=10:1) (Figure 1A). Dynamics of migrating cells infected with either EPEC strain and the commensal $E$. coli strain were evaluated after 2, 6 , 12 , and $24 \mathrm{~h}$. Migration of IEC-6 cells was significantly reduced (compared to a control group) by both EPEC strains at all time-points. In addition, after $6 \mathrm{~h}$, cell migration was reduced by strain E2348/69 compared to LDI001 $(\mathrm{P}<0.0001$; Figure 1B). Furthermore, E. coli strain HS decreased wound migration after $6 \mathrm{~h}$ compared to the control group $(P<0.0001$; Figure $1 B)$. Both EPEC strains inhibited cell migration after $6 \mathrm{~h}$ compared to $E$. coli strain HS $(P<0.05$; Figure $1 B)$. Intestinal cell migration rates from EPEC (E2348/69 and LDI001) strains and E. coli HS infection are observed by representative 24-h microphotographs, as shown in Figure $1 \mathrm{C}$.

Inhibition of intestinal epithelial cell migration by EPEC strains may involve apoptosis and necrosis

There was a greater percentage of apoptotic cells $2 \mathrm{~h}$ $(2.27 \%)$ and $6 \mathrm{~h}(6.63 \%)$ after infection with EPEC strain E2348/69 compared to uninfected cells $(0.91 \%, P=0.0338$ and $1.21 \%, P=0.0258$, respectively). Additionally, EPEC strain E2348/69 (6.63\%) significantly increased cell apoptotic rate relative to $E$. coli strain $\mathrm{HS}(1.81 \%, \mathrm{P}=0.038)$ and EPEC strain LDI001 $(1.70 \%, P=0.0403)$ at $6 \mathrm{~h}$. All groups similarly increased apoptotic cells, with s rates averaging $\sim 10 \%$ at $24 \mathrm{~h}$ (Figure 2A). Moreover, the percentage of necrotic cells was greater in cells infected with EPEC strain E2348/69 (32.61\%; 24.07\%) compared to the uninfected group at 12 and $24 \mathrm{~h}(7.61 \%, \mathrm{P}=0.0263$ and $5.71 \%, \mathrm{P}=$ 0.0292). Furthermore, the percentage of necrotic cells at $12 \mathrm{~h}$ after infection with EPEC strain E2348/69 was increased significantly compared to other infected groups. Moreover, EPEC strain LDI001 (10.33\%) had a significantly higher necrotic cell rate than a control group $(5.71 \%, \mathrm{P}=0.0184)$ at $24 \mathrm{~h}$ (Figure 2B), although there was no significant difference in necrosis between the $E$. coli strain $\mathrm{HS}$ and a control group.

\section{EPEC-induced decrease in intestinal cell migration was T3SS-dependent}

To determine whether the reduction in intestinal migration was mediated by T3SS, a $\triangle e s c F$ EPEC strain, which lacks functioning T3SS, was used. At $2 \mathrm{~h}$, the number of migrating cells infected with EPEC strain E2348/69
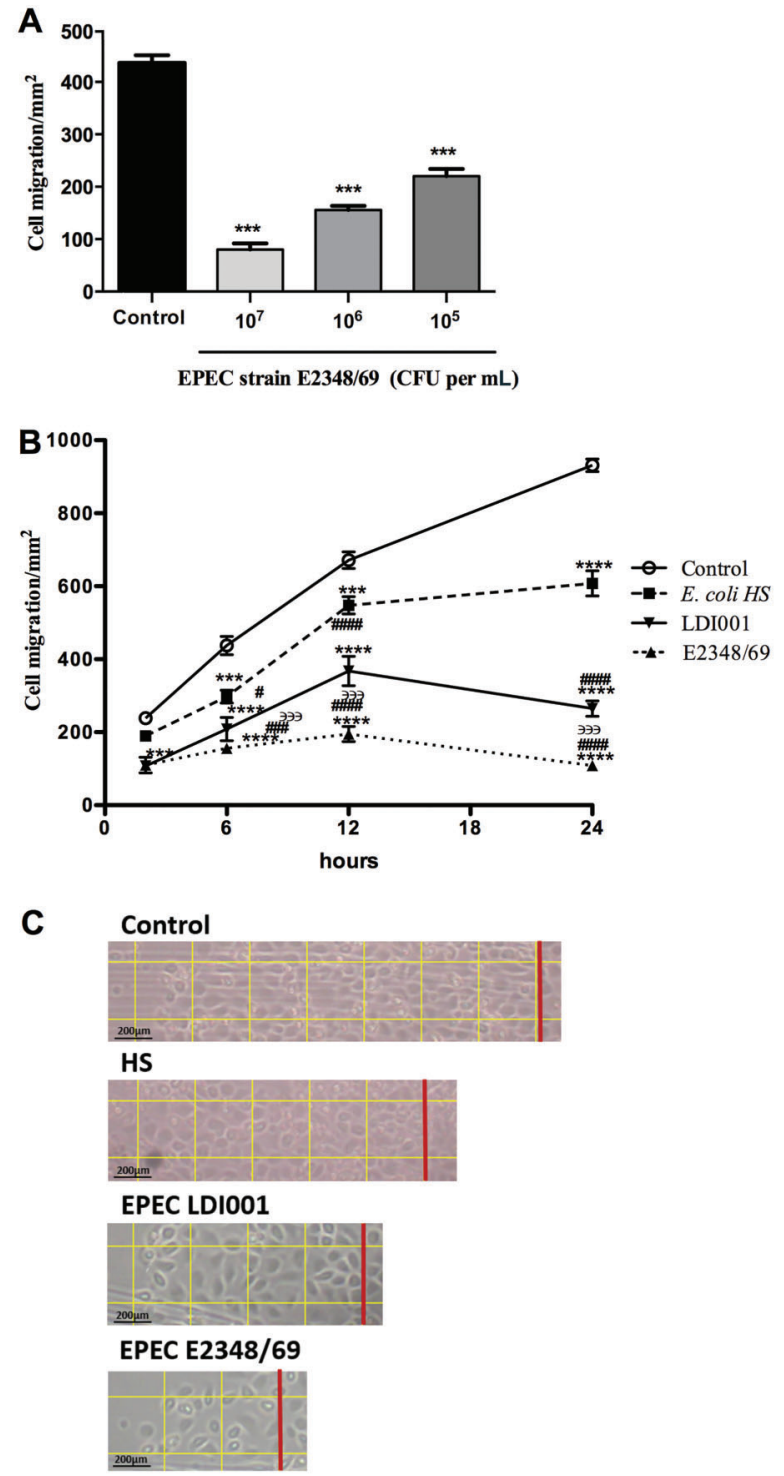

Figure 1. Effects of bacteria on IEC- 6 cell migration. $A$, Concentration analysis of enteropathogenic Escherichia coli (EPEC) strain E2348/69 with $10^{5}, 10^{6}$, and $10^{7}$ cell forming units (CFU) per $\mathrm{mL}$ on cell migration at $6 \mathrm{~h}$ to determine optimum inoculum. $B$, Time-course analysis of damage on intestinal epithelial cells migration induced by EPEC strain E2348/69 and LDI001, and commensal $E$. coli strain HS (inoculum, $10^{6} \mathrm{CFU}$ per $\mathrm{mL}$ ). Data are reported as mean \pm SE of three independent experiments $(n=8) . C$, Intestinal cell migration after $24 \mathrm{~h}$. The red line represents the initial cut and each square has an area of $0.1 \mathrm{~mm}^{2}$. Magnification $10 \times$, bar: $200 \mu \mathrm{m} .{ }^{* \star *} \mathrm{P}<0.001$ and ${ }^{\star \star \star *} \mathrm{P}<0.0001$ vs uninfected control; ${ }^{\#} \mathrm{P}<0.05$, ${ }^{\# \#} \mathrm{P}<0.001$, and ${ }^{\# \# \# P} \mathrm{P}<0.0001$ vs E. coli strain HS; ${ }^{{ }^{э}}{ }^{3} \mathrm{P}<0.001$ vs EPEC strain LDI001 (ANOVA followed by Bonferroni's post-test).

$(37.14 \pm 3.59)$ was decreased compared to a control group (72.85 $\pm 7.46, P=0.0013)$. Furthermore, at 6 and 24 h, E2348/69 and escF complemented EPEC strains 

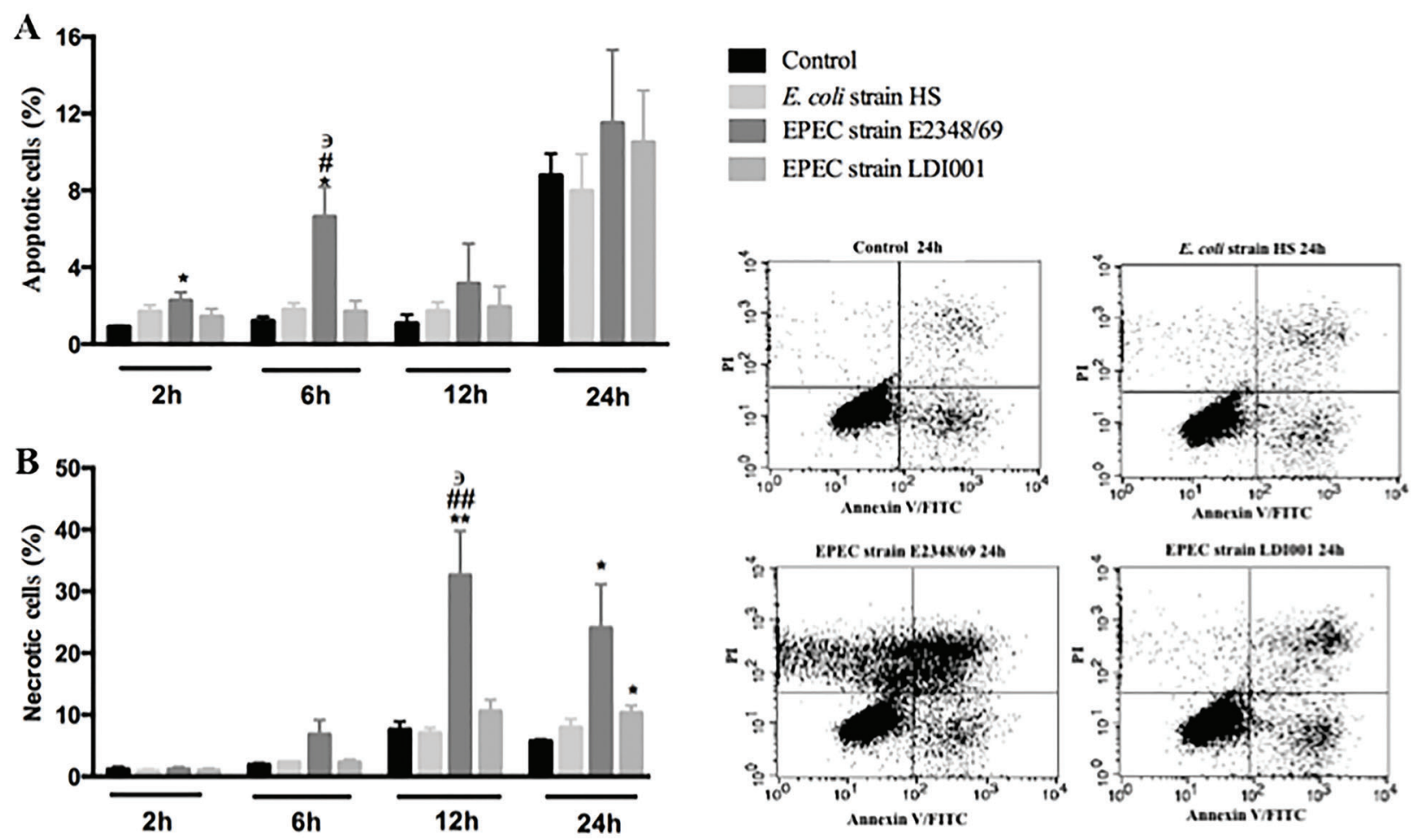

Figure 2. Kinetic analysis of apoptosis $(A)$ and necrosis $(B)$ rates on intestinal epithelial IEC-6 cell induced by enteropathogenic Escherichia coli (EPEC) strains E2348/69 and LDI001 and commensal E. coli strain HS (inocula, $10^{6} \mathrm{CFU}$ per $\mathrm{mL}$ ). Data are reported as mean \pm SE of three independent experiments. ${ }^{*} \mathrm{P}<0.05$ and ${ }^{* *} \mathrm{P}<0.01$ vs uninfected control; ${ }^{\#} \mathrm{P}<0.05$ and ${ }^{\# \#} \mathrm{P}<0.01$ vs $E$. coli strain HS; ${ }^{3} \mathrm{P}<0.05$ vs EPEC strain LDI001 (ANOVA followed by Bonferroni's post-test).

significantly reduced cell migration compared to $\triangle \mathrm{escF}$ EPEC $(P<0.001)$ and control groups $(P<0.0001)$. It was noteworthy that the T3SS-deficient $(\Delta \mathrm{escF})$ EPEC strain did not impair cell migration at any time-point (Figure $3 \mathrm{~A})$. Representative microphotographs of the intestinal migration cells infected by $\Delta e s c F$ and EscF-complemented strain EPEC at $6 \mathrm{~h}$ are shown in Figure 3B.

\section{Regulation of Rho GTPases in intestinal cell migration after EPEC infection}

After $3 \mathrm{~h}$ of EPEC infection, Rac 1 mRNA levels were decreased in cells infected with EPEC E2348/69 (-1.76fold, $P=0.005)$ and escF complemented strains ( -1.31 fold, $\mathrm{P}=0.0457$ ) compared to uninfected cells (Figure 4B). However, there was no significant difference in $R h o A$ and Cdc42 transcription between infected and uninfected IEC6 cells (Figure $4 A$ and $C$ ). Protein Rac 1 was not altered in any group (Figure 5A and $B$ ). However, all pathogenic strains had active Rac1, although this was absent in T3SSdeficient strains (Figure 5C).

\section{Discussion}

In this study, we aimed to investigate the intestinal cell migration impairment caused by two different EPEC strains. We also assessed the involvement of T3SS and Rho GTPases in the process. Overall, we demonstrated that EPEC E2348/69 and LDI001strains inhibited small intestinal epithelial cells migration in vitro. Additionally, necrosis and apoptosis apparently affected this phenomenon. Differential effects of EPEC strains on epithelial injury suggested $e s p L$ and $n l e E$ virulence genes as having potential roles in causing increased damage. Furthermore, T3SS deletion in EPEC E2348/49 did not alter cell migration, and expression of Rho GTPases was not involved.

This was apparently the first study to clarify the dynamics of EPEC effects on intestinal cell migration. Although some studies reported a decrease in migration of stomach cells infected with EPEC $(20,21)$, mechanisms were not investigated. Our group described that infection by enteroaggregative $E$. coli $(\mathrm{EAEC})$ decreased the number of migrating intestinal cells (22), whereas, in the present results, we determined that EPEC strains significantly reduced the number of migrating cells and that bacterial strains differentially inhibited migration. The most considerable reduction in cell migration was due to infection with EPEC strain E2348/69, compared to EPEC LDI001 and $E$. coli $\mathrm{HS}$ strains. In addition, we included a commensal strain to ensure that this was a specific effect of the presence of bacteria or secreted bacterial molecules. 


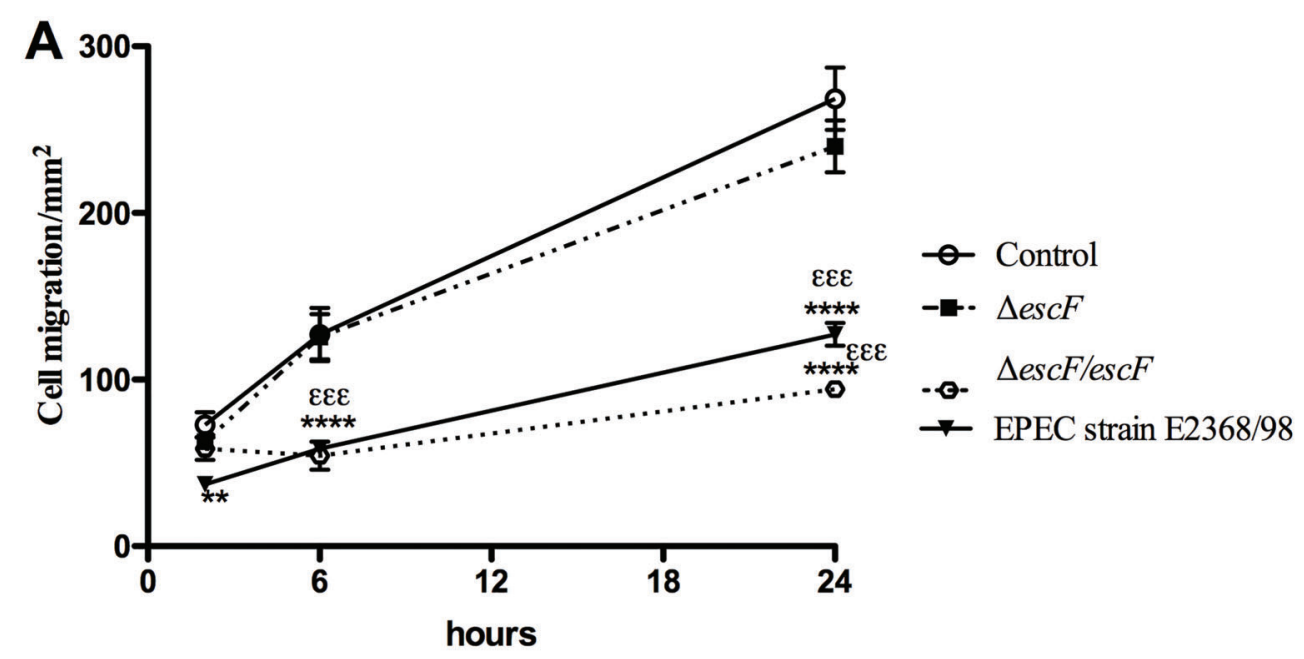

B Initial cut
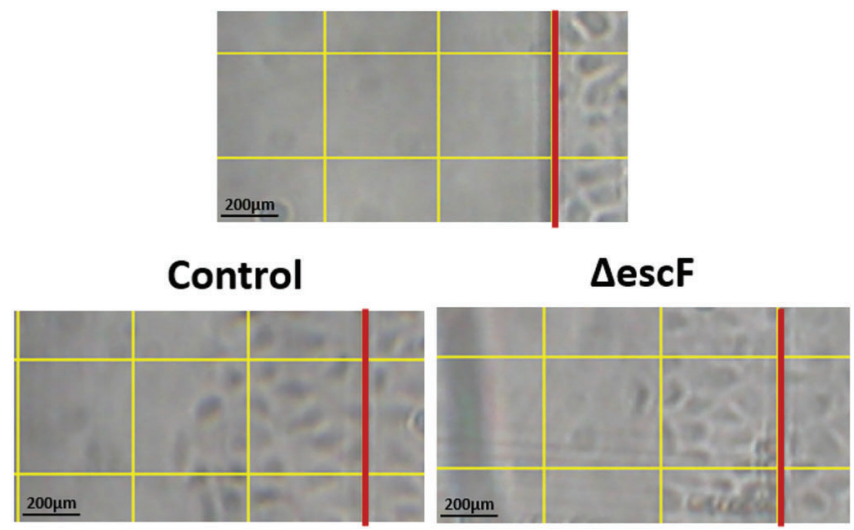

E2348/69
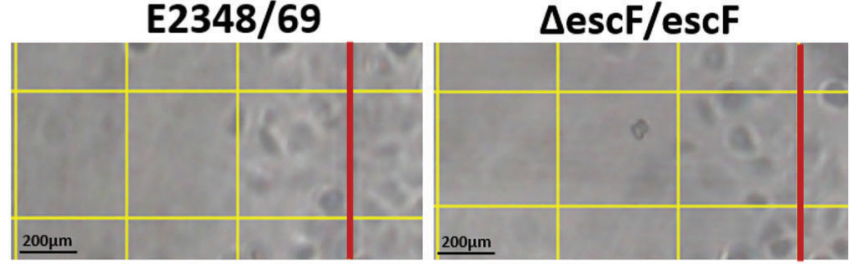

Figure 3. Effects of enteropathogenic Escherichia coli (EPEC) strain E2348/69, EscF-complemented ( $\Delta$ escF/escF), and type III secretion system (T3SS)-deletion mutant $(\triangle e s c F)$ infection on migration of IEC-6 cells $A$. Data are reported as mean \pm SE of three independent experiments $(n=7)$. ${ }^{*} P<0.01$ and ${ }^{* * * *} P<0.001$ vs uninfected control; ${ }^{\varepsilon \varepsilon \varepsilon} P<0.001$ vs $\Delta$ escF EPEC strain (ANOVA followed by Bonferroni's post-test). $B$, Intestinal cell migration after $6 \mathrm{~h}$. The red line represents the initial cut and each square has an area of $0.1 \mathrm{~mm}^{2}$. Magnification $10 \times$, bar: $200 \mu \mathrm{m}$.

Interestingly, E. coli strain HS also inhibited migration of intestinal cells; however, this effect was significantly less pronounced compared to pathogenic strains. Bacterial lipopolysaccharide significantly inhibited migration of IEC-6 cells across a wound, both in an animal model and in vitro, and this may explain the E. coli HS findings (23).
We determined whether cell death affected migration of intestinal cells. Initially, cell death caused by EPEC strains E2348/69 caused a slight increase in the percentage of apoptotic cells at early time-points, whereas strain LDI001 did not induce apoptosis, suggesting that other bacterial factors are necessary to decrease cell migration. 

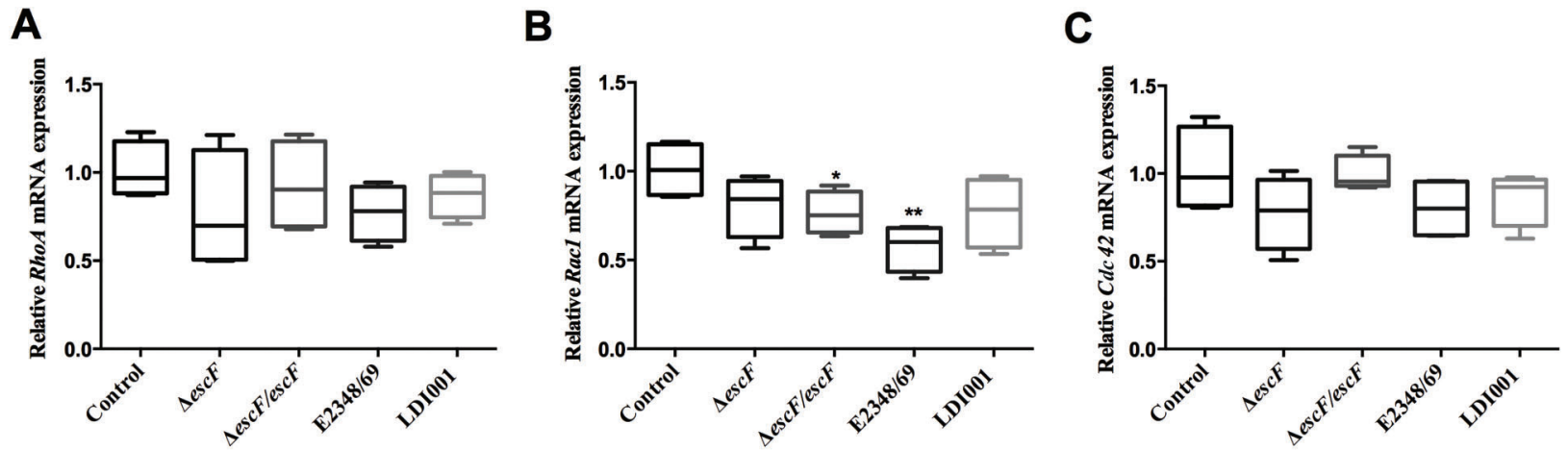

Figure 4. Expression of the transcription of small Rho GTPases RhoA $(A), \operatorname{Rac1}(B)$, and $C d c 42(C)$ by IEC-6 cells after infection with enteropathogenic Escherichia coli (EPEC) strain E2348/69, EscF-complemented ( $\triangle$ escFlescF) and T3SS-deletion mutant ( $\triangle$ escF). Results were determined by quantitative RT-PCR and normalized to ywhaz (housekeeping gene) and were performed by the ${ }^{\Delta \Lambda} \mathrm{CT}$ method. Data are reported as means \pm SE of three independent experiments. ${ }^{*} \mathrm{P}<0.05$ and ${ }^{* *} \mathrm{P}<0.01$ vs uninfected control (ANOVA followed by Bonferroni's post-test).

In contrast, high (E2348/69) and moderate (LDI001) rates of necrosis at the end of the experiment may have had a greater impact on reductions in wound migration. In an in vitro study using Clostridium difficile toxin A, inhibitory effects on cell migration were associated with cell death (24). Our present results agree with those of Abul-Milh et al. (25) who reported increased necrosis in cells infected with EPEC strain E2348/69. Moreover, some virulence factors, e.g., BFP, Map, and $\mathrm{EspH}$, were shown to induce cell death (26), and both EPEC strains in the present study had genes for these effectors. Thus, these genes could be responsible for cell death induction by the strains studied, however specific mutant strains should be constructed to prove such hypothesis.

Interestingly, we identified varying degrees of impairment in cell migration and cell death caused by the two wild-type EPEC strains. EPEC strain E2348/69 induced greater epithelial injury than EPEC strain LDI001. The different profiles of virulence-related genes between these strains, notably the absence of espL and nleE genes in the EPEC strain LDI001 (whereas EPEC E2348/69 harbors all of them), suggests a vital role of these virulence factors on the EPEC-induced epithelial injury, and the use of specific mutant strains could confirm this finding. The EspL effector is encoded by two genes, espL1 (pseudogene) and espL2 (both targeted by primers used in this study). Of these, espL2 is very similar to EHEC espL2, which interacts with annexin-2, leading to condensation of actin fibers and formation of a pseudopod-like structure (27). NleE, a nonLEE effector protein, is also encoded by the genes nleE1 and nleE2 (both targeted by primers used in this study) and seems to modulate the immune response through inhibition of NF-kB by a T3SS-dependent mechanism $(11,28)$. Additionally, it induces polymorphonuclear leukocyte transepithelial migration in vitro (29). In support of our data, in a broad investigation of EPEC virulence factors by oligonucleotide array in strains isolated from children from a case-control study of diarrhea in Norway, genes from a pathogenicity island, including $n l e E$ and espL, were significantly more common in isolates from children with diarrhea (30). It is noteworthy that the EPEC strain E2348/69 was initially isolated from an acute diarrhea case (31), whereas LDI001 was isolated from a malnourished child without diarrhea. Although further genomic investigations are required to distinguish genetics of these EPEC strains, this study demonstrated a clear evidence of these differences. Additionally, clear outcomes from each strain were consistent with different effects on intestinal epithelial cells. Overall, our results corroborate crucial effects of these genes on the severity of EPEC infections.

To investigate the mechanisms utilized by EPEC to reduce the intestinal cell migration, a T3SS-deficient $(\triangle e s c F)$ EPEC strain was used. Initially, EPEC E2348/69 and T3SS-complemented strains inhibited cell migration; conversely, $\Delta e s c F$ EPEC did not reduce migration significantly. Therefore, we inferred that the presence of T3SS might have a role in reducing cell migration. In that regard, T3SS has a fundamental role in EPEC infection, as this system provides a portal whereby many effector proteins that affect the organization of the cell cytoskeleton are injected into host cells (32). Disassembly of cytoskeleton organization might compromise cell migration. In addition, in other in vitro and in vivo studies, deletions of various T3SS effectors of $A / E$ pathogens were implicated in reducing disease severity that interferes with the formation of $A / E$ lesions and avoiding epithelial barrier damage $(33,34)$. Furthermore, other non-T3SS-dependent virulenceassociated proteins were described in A/E pathogens (35). Some studies demonstrated that additional putative virulence factors, non-T3SS-dependent, such as pili and adhesins, were also necessary to achieve colonization in animal or cellular models $(36,37)$.

The Rho GTPase proteins have a critical role in cytoskeletal rearrangement, and its activity is altered by 


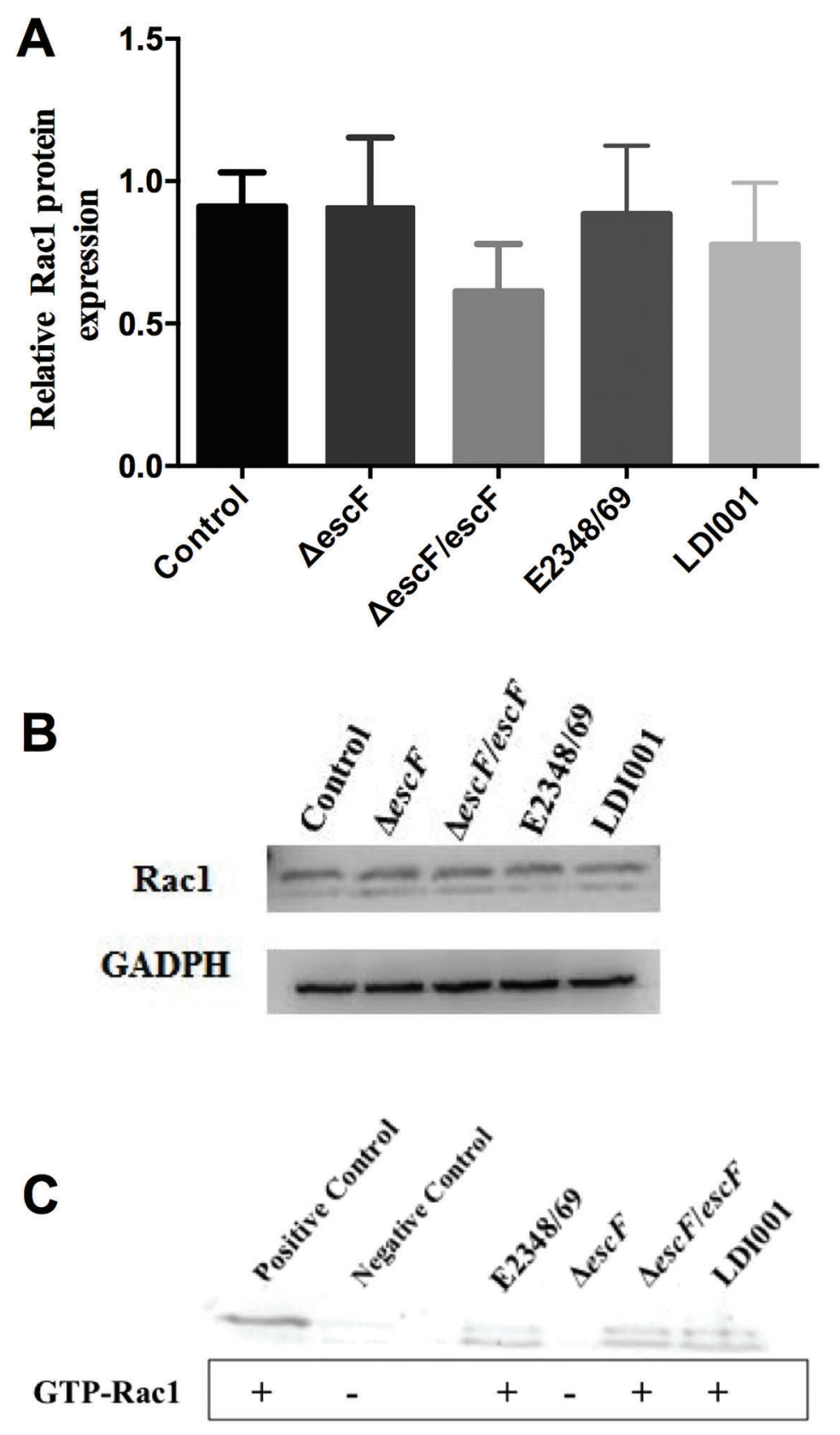

Figure 5. Enteropathogenic Escherichia coli (EPEC) strains E2348/69, EscF-complemented $(\triangle \mathrm{escF} / \mathrm{esc} F)$ and T3SS-deletion mutant $(\triangle \mathrm{esc} F)$ infection did not affect protein expression of Rac1 in IEC-6 cells (western blot analysis) ( $A$ and $B$ ). EPEC strains, except the type III secretion system (T3SS)-deficient strain, promoted Rac1 activation (C). Data are reported as means \pm SE of three independent experiments.

Racl

GADPH

EPEC effector proteins (38). Therefore, we determined whether EPEC strains altered expression of RhoA, Rac1, and Cdc42. In the present study, only levels of Rac1 transcription were significantly decreased by EPEC strain E2348/69 and LDI001 at $3 \mathrm{~h}$ after infection, although levels of Rac 1 protein were not reduced by EPEC infection. However, Rac1 was active in all EPEC strains, except the T3SS-deficient strain. Therefore, we inferred that Rac-1 activation could have a role in the impairment of intestinal cell migration. In a previous study (38), Rac1 activating effectors, EspT and SopE, decreased cell detachment. As cell detachment is one of the steps of cell migration (10), we speculated that Rac1 activation delayed cell detachment and thereby reduced cell movement. Depending on the cell type and stimulus, active Rac1 could either promote or suppress cell migration. For example, melatonin reduces migration of endothelial cells through inhibition of Rac1 activation (39), whereas infection of gastric epithelial cells 
with EPEC reduces cell migration associated with Rac1 inhibition (21). Based on the present study, we inferred that the decline of intestinal epithelial cell migration infected by EPEC occurred via activation of Rac1.

In conclusion, we inferred that EPEC strains altered intestinal epithelial cell migration in vitro via more than one mechanism and that this phenomenon may or may not be associated with cell death. Differences among wild-type strains in virulence genes profiles may account for different effects, with potential for espL and nleE genes having significant roles in impairment of cell migration. However, further studies are necessary to confirm the involvement of these virulence genes in intestinal cell migration. Moreover, the EPEC type III secretion system may be involved in inhibition of intestinal epithelial cell migration by EPEC 2348/69, as its deletion prevented the effect, which occurs through activation of Rac1. These data contributed to emerging basic and applied knowledge regarding pathobiology of EPEC infection

\section{References}

1. Kotloff KL, Nataro JP, Blackwelder WC, Nasrin D, Farag TH, Panchalingam S, et al. Burden and aetiology of diarrhoeal disease in infants and young children in developing countries (the global enteric multicenter study, GEMS): a prospective, case-control study. Lancet 2013; 382: 209-222, doi: 10.1016/S0140-6736(13)60844-2.

2. Alikhani MY, Mirsalehian A, Aslani MM. Detection of typical and atypical enteropathogenic Escherichia coli (EPEC) in Iranian children with and without diarrhoea. J Med Microbiol 2006; 55: 1159-1163, doi: 10.1099/jmm.0.46539-0.

3. Vieira MA, Dos Santos LF, Dias RC, Camargo CH, Pinheiro SR, Gomes TA, et al. Atypical enteropathogenic Escherichia coli as etiologic agents of sporadic and outbreak-associated diarrhea in Brazil. J Med Microbiol 2016; 65: 998-1006, doi: 10.1099/jmm.0.000313.

4. Croxen MA, Law RJ, Scholz R, Keeney KM, Wlodarska M, Finlay BB. Recent advances in understanding enteric pathogenic Escherichia coli. Clin Microbiol Rev 2013; 26: 822-880, doi: 10.1128/CMR.00022-13.

5. Lapointe TK, O'Connor PM, Buret AG. The role of epithelial malfunction in the pathogenesis of enteropathogenic E. coliinduced diarrhea. Lab Invest 2009; 89: 964-970, doi: 10.1038/labinvest.2009.69.

6. Zhang Q, Li Q, Wang C, Li N, Li J. Redistribution of tight junction proteins during EPEC infection in vivo. Inflammation 2012; 35: 23-32, doi: 10.1007/s10753-010-9285-1.

7. Donnenberg MS, Finlay BB. Combating enteropathogenic Escherichia coli (EPEC) infections: the way forward. Trends Microbiol 2013; 21: 317-319, doi: 10.1016/j.tim.2013.05.003.

8. Blikslager AT, Moeser AJ, Gookin JL, Jones SL, Odle J. Restoration of barrier function in injured intestinal mucosa. Physiol Rev 2007; 87: 545-564, doi: 10.1152/physrev. 00012.2006 .

9. Ridley AJ. Rho GTPase signalling in cell migration. Curr Opin Cell Biol 2015; 36: 103-112, doi: 10.1016/j.ceb.2015. 08.005 . and its association with the restoration of intestinal barrier functions after epithelial damage.

\section{Supplementary Material}

Click here to view [pdf]

\section{Acknowledgments}

We thank the technicians and staff of the Clinical Research Unit and Institute of Biomedicine at the Federal University of Ceará for their support for this research. We also thank Dr. James Nataro (University of Virginia) and Dr. Michael Donnenberg (University of Maryland) for kindly providing $E$. coli strains. The Conselho Nacional de Desenvolvimento Científico e Tecnológico (CNPq Grants: 503442/2008-9 and 573928/2008-8) and Fundação Cearense de Apoio ao Desenvolvimento Científico e Tecnológico (FUNCAP) provided financial support for these studies.

10. Ridley AJ, Schwartz MA, Burridge K, Firtel RA, Ginsberg $\mathrm{MH}$, Borisy $\mathrm{G}$, et al. Cell migration: integrating signals from front to back. Science 2003; 302: 1704-1709, doi: 10.1126/ science.1092053.

11. Wong AR, Pearson JS, Bright MD, Munera D, Robinson KS, Lee SF, et al. Enteropathogenic and enterohaemorrhagic Escherichia coli: even more subversive elements. Mol Microbiol 2011; 80: 1420-1438, doi: 10.1111/j.1365-2958. 2011.07661.x.

12. Lima AAM, Oriá RB, Soares AM, Filho JQ, de Sousa JrF, Abreu C, et al. Geography, population, demography, socioeconomic, anthropometry, and environmental status in the MAL-ED cohort and case-control study sites in Fortaleza, Ceará, Brazil. Clin Infect Dis 2014; 59(Suppl 4): S287-S294, doi: $10.1093 /$ cid/ciu438.

13. Houpt E, Gratz J, Kosek M, Zaidi AK, Qureshi S, Kang G et al. Microbiologic methods utilized in the MAL-ED cohort study. Clin Infect Dis 2014; 59(S4): S225-S232, doi: 10.1093/ cid/ciu413.

14. Cravioto A, Tello A, Navarro A, Ruiz J, Villafán H, Uribe F, et al. Association of Escherichia coli HEp-2 adherence patterns with type and duration of diarrhoea. Lancet 1991; 337: 262-264, doi: 10.1016/0140-6736(91)90868-P.

15. Long TM, Nisa S, Donnenberg MS, Hassel BA. Enteropathogenic Escherichia coli inhibits type I interferon- and RNase L-mediated host defense to disrupt intestinal epithelial cell barrier function. Infect Immun 2014; 82: 2802-2814, doi: 10.1128/IAI.00105-14.

16. Braga-Neto MB, Warren CA, Oriá RB, Monteiro MS, Maciel $A A$, Brito GA, et al. Alanyl-glutamine and glutamine supplementation improves 5-fluorouracil-induced intestinal epithelium damage in vitro. Dig Dis Sci 2008; 53: 2687-2696, doi: 10.1007/s10620-008-0215-0.

17. Li L, Li J, Wang JY, Yang CQ, Jia ML, Jiang W. Role of RhoA in platelet-derived growth factor-BB-induced migration of rat hepatic stellate cells. Chin Med J 2010; 123: 2502-2509. 
18. Beige F, Friedric M, Probst C, Sotlar K, Goke B, Diegelmann $J$, et al. Oncostatin M mediates STAT3-dependent intestinal epithelial restitution via increased cell proliferation, decreased apoptosis and upregulation of SERPIN family members. PLoS One 2014; 9: e93498, doi: 10.1371/journal.pone. 0093498.

19. Livak KJ, Schmittgen TD. Analysis of relative gene expression data using real-time quantitative PCR and the 2(-Delta Delta C(T)) Method. Methods 2001; 25: 402-408, doi: 10.1006/ meth.2001.1262.

20. Backert S, Kenny B, Gerhard R, Tegtmeyer N, Brandt S. PKA-mediated phosphorylation of EPEC-Tir at serine residues 434 and 463: A novel pathway in regulating Rac1 GTPase function. Gut Microbes 2010; 1: 94-99, doi: 10.4161/ gmic.1.2.11437.

21. Brandt S, Kenny B, Rohde M, Martinez-Quiles N, Backert S. Dual infection system identifies a crucial role for PKAmediated serine phosphorylation of the EPEC-Tir-injected effector protein in regulating Rac1 function. Cell Microbiol 2009; 11: 1254-1271, doi: 10.1111/j.1462-5822.2009.01330.x.

22. Carvalho EB, Maga EA, Quetz JS, Lima IF, Magalhães HY, Rodrigues FA, et al. Goat milk with and without increased concentrations of lysozyme improves repair of intestinal cell damage induced by enteroaggregative Escherichia coli. BMC Gastroenterol 2012; 12: 106, doi: 10.1186/1471-230X12-106.

23. Cetin S, Ford HR, Sysko LR, Agarwal C, Wang J, Neal MD, et al. Endotoxin inhibits intestinal epithelial restitution through activation of Rho-GTPase and increased focal adhesions. J Biol Chem 2004; 279: 24592-24600, doi: 10.1074/jbc. M313620200.

24. Brito GA, Carneiro-Filho B, Oriá RB, Destura RV, Lima AA, Guerrant RL. Clostridium difficile toxin A induces intestinal epithelial cell apoptosis and damage: role of GIn and Ala-GIn in toxin A effects. Dig Dis Sci 2005; 50: 1271-1278, doi: 10.1007/s10620-005-2771-x.

25. Abul-Milh M, Wu Y, Lau B, Lingwood CA, Barnett Foster D. Induction of epithelial cell death including apoptosis by enteropathogenic Escherichia coli expressing bundle-forming pili. Infect Immun 2001; 69: 7356-7364, doi: 10.1128/ IAI.69.12.7356-7364.2001.

26. Wong Fok Lung T, Pearson JS, Schuelein R, Hartland EL. The cell death response to enteropathogenic Escherichia coli infection. Cell Microbiol 2014; 16(12): 1736-1745, doi: 10.1111/cmi.12371.

27. Tobe T. Cytoskeleton-modulating effectors of enteropathogenic and enterohemorrhagic Escherichia coli: role of EspL2 in adherence and an alternative pathway for modulat ing cytoskeleton through Annexin A2 function. FEBS $J$ 2010; 277: 2403-2408, doi: 10.1111/j.1742-4658.2010. 07654.x.

28. Nadler C, Baruch K, Kobi S, Mills E, Haviv G, Farago M, et al. The type III secretion effector NleE inhibits NF-kappaB activation. PLoS Pathog 2010; 6: e1000743, doi: 10.1371/ journal.ppat.1000743.

29. Zurawski DV, Mumy KL, Badea L, Prentice JA, Hartland EL, McCormick BA, et al. The NleE/OspZ family of effector proteins is required for polymorphonuclear transepithelial migration, a characteristic shared by enteropathogenic Escherichia coli and Shigella flexneri infections. Infect Immun 2008; 76: 369-379, doi: 10.1128/IAl.00684-07.

30. Afset JE, Bruant G, Brousseau R, Harel J, Anderssen E, Bevanger $L$, et al. Identification of virulence genes linked with diarrhea due to atypical enteropathogenic Escherichia coli by DNA Microarray Analysis and PCR. J Clin Microbiol 2006; 44: 3703-3711, doi: 10.1128/JCM.00429-06.

31. Iguchi A, Thomson NR, Ogura $Y$, Saunders $D$, Ooka T, Henderson IR, et al. Complete genome sequence and comparative genome analysis of enteropathogenic Escherichia coli O127:H6 strain E2348/69. J Bacteriol 2009; 191: 347354, doi: 10.1128/JB.01238-08.

32. Navarro-Garcia F, Serapio-Palacios A, Ugalde-Silva P, Tapia-Pastrana G, Chavez-Dueñas L. Actin cytoskeleton manipulation by effector proteins secreted by diarrheagenic Escherichia coli pathotypes. Biomed Res Int 2013; 374395, doi: $10.1155 / 2013 / 374395$

33. Coburn B, Sekirov I, Finlay BB. Type III secretion systems and disease. Clin Microbiol Rev 2007; 20: 535-549, doi: 10.1128/CMR.00013-07.

34. Hardwidge PR, Rodriguez-Escudero I, Goode D, Donohoe $\mathrm{S}$, Eng J, Goodlett DR, et al. Proteomic analysis of the intestinal epithelial cell response to enteropathogenic Escherichia coli. J Biol Chem 2004; 279: 20127-20136, doi: 10.1074/jbc.M401228200.

35. Navarro-García F, Canizalez-Roman A, Sui BQ, Nataro JP, Azamar $Y$. The serine protease motif of EspC from enteropathogenic Escherichia coli produces epithelial damage by a mechanism different from that of pet toxin from enteroaggregative E. coli. Infect Immun 2004; 72: 3609-3621, doi: 10.1128/IAI.72.6.3609-3621.2004.

36. Badea L, Doughty S, Nicholls L, Sloan J, Robins-Browne RM, Hartland EL. Contribution of Efa1/LifA to the adherence of enteropathogenic Escherichia coli to epithelial cells. Microb Pathog 2003; 34: 205-215, doi: 10.1016/S08824010(03)00026-3.

37. Stevens MP, van Diemen PM, Frankel G, Phillips AD, Wallis TS. Efa1 influences colonization of the bovine intestine by shiga toxin-producing Escherichia coli serotypes 05 and O111. Infect Immun 2002; 70: 5158-5166, doi: 10.1128/ IAI.70.9.5158-5166.2002.

38. Wong AR, Clements A, Raymond B, Crepin VF, Frankel G. The interplay between the Escherichia coli Rho guanine nucleotide exchange factor effectors and the mammalian RhoGEF inhibitor EspH. MBio 2012; 3: e00250-11, doi: 10.1128/mBio.00250-11.

39. Yang L, Zheng J, Xu R, Zhang Y, Gu L, Dong J, et al. Melatonin suppresses hypoxia-induced migration of HUVECs via inhibition of ERK/Rac1 activation. Int J Mol Sci 2014; 15: 14102-14121, doi: 10.3390/jims150814102.

40. Rasko DA, Rosovitz MJ, Myers GS, Mongodin EF, Fricke WF, Gajer $P$, et al. The pangenome structure of Escherichia coli: comparative genomic analysis of $\mathrm{E}$. coli commensal and pathogenic isolates. J Bacteriol 2008; 190: 6881-6893, doi: 10.1128/JB.00619-08. 